\title{
The role of experiential learning in creative design appreciation among TDS students at Taylor's University
}

\author{
Mohd Asrizal Razali \\ The Design School \\ Taylor's University \\ Kuala Lumpur, Malaysia \\ mohdasrizal.razali@taylors.edu.my
}

\author{
Noranis Ismail \\ The Design School \\ Taylor's University \\ Kuala Lumpur, Malaysia \\ noranis.ismail@taylors.edu.my
}

\author{
Nurzihan Hassim \\ School of Communication \\ Taylor's University \\ Kuala Lumpur, Malaysia \\ nurzihan.hassim@taylors.edu.my
}

\begin{abstract}
Whilst $21^{\text {st }}$ century education is increasingly driven by technology, a holistic learning experience is still largely reliant on traditional pedagogies. This study focused on experiential learning that inspired design thinking among Taylor's University students where creative cities were visited to heighten appreciation and understanding of arts and design movements. Previous research identified that learners are immersed in methods that suit their aptitude and selfconfidence built in their prior learning, whereas the presence of a facilitator provides a nurturing setting and allows the learner to utilize their analytical skills in conceptualizing and processing new knowledge. In addition, it was proposed that individual learning styles are significant influences towards experiential learning. This study examined perceptions of students and elements of experiential learning incorporated during their excursion. In doing so, the similarities and differences of their individual reflections and continuance intention towards the learning experience warranted further exploration.
\end{abstract}

Keywords Experiential learning, design thinking, communication design, education media, reflective learning.

\section{INTRODUCTION}

Teaching and learning in higher education at present are increasingly active beyond the four walls of classroom environments as there is significant increase in participation and encouraging feedback from learners on non-traditional teaching methods [1]. In Malaysia, blended learning, elearning and virtual classrooms are gaining popularity in public and private colleges and universities. Subsequently, conventional method such as face-to-face interaction is given less attention as the current trends in Malaysian higher education are focused on four factors; globalization, teaching and learning, governance and knowledge-based society [2].Nevertheless, experiential learning is equally crucial to the learner progress and takes place when; i) a person is involved in an activity, ii) he or she looks back and evaluates it, iii) determines what was useful or important to remember, and iv) uses this information to perform another activity [3]. Another study summed experiential learning as direct encounters with the phenomena being studied rather than thinking or considering the possibility of doing something about it [4]. Additionally, student holds much of the responsibility in the learning process whereby they manage their own learning, rather than being told what to do and when to do it [5]. New skills, new attitudes, or new ways of thinking are also able to develop through experiential education where it immerses learners in an experience and then encourages reflection about the experience [6].

More importantly, graduates who are skilled will be relevant, responsive and work-ready to start ahead in the global marketplace in a highly competitive and challenging modern workplace that is in line with $4^{\text {th }}$ Industrial Revolution. Taylor's University (TU), introduced Taylor's Graduate Capabilities (TGC) in 2007 to meet the ever changing demands of industry, community and globalisation. The TGC outlined the core knowledge, skills, abilities and qualities that learners will develop at the university [7]. One of the identified skills emphasized within the TGC is "lifelong learning" in which graduates are required to utilize, synthesize and utilize information effectively to continually become intellectually engaged in the fields they would soon be part of. For this reason, The Design School (TDS) at TU embarks on a yearly experiential-immersive learning approach that complements theories learned in the classroom through excursions to foreign creative cities that aim to achieve module outcomes and required levels of design literacy as well as application. The international trips are organized to enrich learners with foreign cultures, vast arts and trademark design elements by visiting museums, galleries, art markets and attending live art performances. The objective of these excursions is to elevate experiential learning, create a more holistic learning experience and enable cultural exchange among the learners. In addition, the individual differences of learners from their unique learning styles emerge [8] and are congruent to the development of the TGC by the university.

\section{LITERATURE REVIEW}

In education, life experience and learning form an intriguing and complex relationship. Kolb's experiential learning model appeals to higher education where learning is shaped from the transforming experience into knowledge [9]. Experiential learning contrasted with classroom settings as the learner is exposed to direct sense experience and incontext action controlled by the individual. It has been shown that this method of learning takes place by taking apart and putting together the structures that give lives meaning, particularly coherent and meaningful experiences [10].

Current educators are burdened with the need to accommodate to digital natives known as "Generation Z" who are commonly technologically savvy thus becoming major distractions to their learning attitudes, where they are more self-centric and networked among themselves [11]. Ranai [12] had emphasised on two important 
learning styles of independent study (heutagogy) and peer-oriented learning (paragogy) that could bridge to the large gap between the learners' advanced digital media literacy and the diminishing attention towards traditional teaching methods.

Richardson et al. [13] also asserted that the learner community is still in need of social presence, teaching presence and cognitive presence, despite the emergence of e-learning for educational efficiency. Studies have highlighted individuality of the learner as their progressions are highly mediated by themselves with aid from facilitators, whereas their conceptual understanding is dependent on the exchange of cognitive transactions between peers [14], [15], [16]. Individual learning behaviour was long studied by Honey and Mumford [17] who established four learner perspectives into Activists, Theorists, Reflectors and Pragmatists; where Activists were observed to have more enthusiasm in hands-on activities. Theorists utilize their analytical skills more than other learners while Reflectors dwell more into problem-solving tasks. Pragmatists are identified to be keener on attending to real-world case studies that could be utilized for future work-related situations. Other learning style indexes (LSI) such as Myers-Briggs Type Indicator [18] had similarly postulated that learners prefer to utilize their senses in order to achieve concrete experience of a learning activity and are more attentive to details that are relatable to real-world instances. MyersBriggs further identified "intuitive learners" who are far keener on dissecting abstract concepts through theories. Meanwhile, Pask [19] defined learning styles as visual and spatial skills with understanding of global awareness and citizenship. While Myers-Briggs rely on a step-bystep evaluation by the learner, Pask's global learners absorb learning material as quickly as possible to draw a framework of ideas and understanding in which education is meant to be superficial and analogous among mutual learners for further dissection with one another. This is in contrast to the Kolb Learning Style Index where the four quadrants of learning behaviours namely the Diverger, Assimilator, Accommodator and Converger are each required by the learner to complete the full knowledgeacquiring cycle whilst at the same time indicating four different categories of learners [20]. As explained by the subsequent studies [8], [21] the Divergers (feel and watch), are described as "concrete experiencers" or "reflective observers" who are analytical about tasks given to them and tend to have a holistic overview prior to completing it. They are also keen on intellectual engagements so they can learn from it. Next, the Convergers (think and do) dwell mostly in abstract conceptualization and are known as active experimenters who are willing to attempt trial and errors while prefer to work independently. They attempt to understand through reviewing the situation and finding meaning behind the experience. Subsequently, the Accommodators who are considered "concrete experiencers" or "active experimenters" (feel and do) are the most hands-on with a lot more tendency to take action and are also by most part are independent learners where they tend to test concepts in different and new situations to discover ways to improve. Lastly, the Assimilators are "abstract conceptualizers" or "reflective observers" (think and watch) who spend time in decision making and structured understanding. They also prefer a lot more facilitators and demonstrations prior to completing tasks themselves to ensure that they are indeed on the right path. They tend to identify recurring themes, problems and/or issues that will help them with new learning experience.

The weakness of this theory lies in its adaption from the Lewinian model of Action Research and Laboratory training. Kolb highlighted that effective learning can only take place when an individual completes a cycle of the proposed Lewinian four-stage model: concrete experience, reflective observation, abstract conceptualization and active experimentation. Each of these stages encourages the learners to examine their experiences through different reflective practices of feeling, watching, thinking and doing [3] .

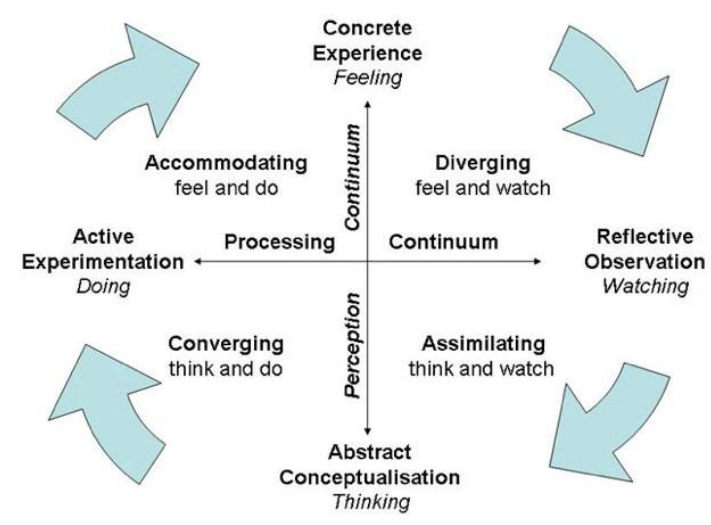

Figure. 1. McLeod(2017) Summary of Kolb's Learning Style Index (LSI) through a process continuum

\section{PROBLEM STATEMENT}

Kolb's LSI theory treats learning as a linear process where one continuously creates and implements ideas for improvement in stages. Ideally, the learner should fit any of the criteria identified by having the abilities to either be actively involved in the experience; be able to reflect on the experience; possess and use analytical skills to conceptualize the experience; and possess decision making and problem solving skills in order to use the new ideas gained from the experience. Henceforth, this signifies a significant gap in studies of Kolb's LSI that are seen as a continuous learning process as each process already defines the dynamic characteristics of individualistic learners despite the characteristics being separate or parallel to one another. This present study intends to analyse the congruence of experiential learning elements through learner perceptions in their knowledgeacquiring process. The utilizing of specific learning styles to appreciate creative design work to enhance lifelong learning for design school learners warranted further exploration in the context of experiential learning, particularly with the varied and presentations of arts and design movements of different cultures that could also benefit other design learners and educators in their teaching approach. 


\section{METHODOLOGY}

In order to examine the role of experiential learning in the study of contemporary and modern design as well as its incorporation in the learner's progress and task outcome, content analysis was deployed on data collected through reflective essays of 23 participants to a study excursion organized by Taylor's University Design School to Berlin Germany. The data were collected upon the completion of the semester and was analysed using Atlas.ti CAQDAS software. The data were then simultaneously coded to ascertain patterns relevant to the literature review and research questions. Subsequently, subcategories were identified branching from and matching with key coding terms based on the literature on Kolb's Learning Style Index [8] to determine the forms of experiential learning observed in this present study . From the coding of data, four main key coding areas or groups were established namely; 1) doing, 2) feeling, 3) thinking; and 4) watching. The quotations highlighted from the reflective essays of the learners were organized into to determine the roles and implications of experiential learning upon Taylor's University Design School learner (TDS).

As recommended by Schreier [22] any emergent themes that was present during the coding was also included as subcategories. The data analysis and reporting was done based on the logical flow of issues discussed in this paper, particularly whether the study excursion participated by the learners engaged with their learning styles or were present within the learning excursion experience. The study constructed an inductive and thematic structure to narrate the findings from a macro level and later broke down the findings into larger meanings to identify the constructs built by learners in shaping their attitudes and behaviours towards their study excursion which goes beyond the classroom. Select quotations were featured for each category and its subcategories to illustrate the significance themes presented.

\section{FINDINGS AND ANALYSIS}

From the data collected, a total of 268 main quotations were highlighted and segmented in Figure 1. There is an balance in the styles displayed by learners during the experiential trip to Berlin to study art and design beyond the classroom. However, there is a significant slant towards "Feel" and "Watch" which denotes that the students are mostly from the "Diverger" category.

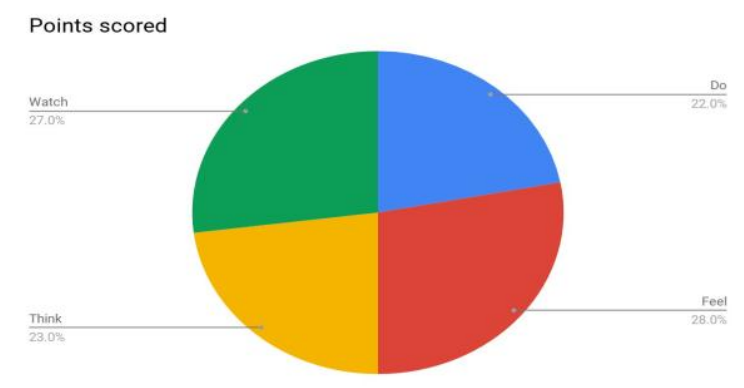

Figure. 2. Segmentation of learning styles applied during Berlin study trip excursion
While Kolb's Learning Style Index (LSI) could not specifically pinpoint to individual behavioural categories, the group of learners can be collectively considered as "Divergers" who believe in concrete experiences and who thoroughly analyse tasks given to them, resulting in the a total of 20 subcategories of codes that were established in which they were all arranged and organized into the aforesaid four main groups. Additionally the group of students also believe in comprehensively reviewing ideas first and seek constructive feedback while avoiding conflicts in their reflective observations [23]. The following sections will detail three subcategories that are among the highest in rank of quotations coded in the "Feel" and "Watch" code group respectively to further ascertain the learners' perceptions and the role of their experiential learning to gain and apply new information and knowledge.

Concrete Experience

During the excursion, the concrete experiences of the students played a major part in their receptiveness and adaptation of the experiential learning and conceptualization of new knowledge in art and design. Being put in a positive environment filled with design inspirations from renowned artists was imperative to their attitudes towards the excursion.

\section{A. Feel - Emotions}

Informant 3 immediately felt a sense of motivation after being put in a different environment compared to her home ground. She found that the location of Berlin was ideal to capture picturesque moments and become quickly adaptive to ideas of beauty that could inspire her work.

"... I fell in love with the autumn aesthetic. The beautiful brown leaves covering the ground. I once saw a mountain of fallen leaves on the corner and I wanted to jump onto it just to see it covering the ground, flying in the air. I took plenty of time to capture the autumn beauty with my camera. It was something worth to capture. “

To concur with Informant 3, Informant 11 also felt that Berlin was an ultimate canvas of art that immediately gave ideas for her artwork.

"In Berlin, everything seems so unreal. I felt a current of cool air blowing in my face. The sceneries were breathtaking. The colours of the trees are simply beautiful, I remembered telling my friend, "I wish I could use "eyedropper" to save all these colours."

Meanwhile, Informant 2 believed that what was seen in Berlin was surreal and captivating compared to experiencing the city and its art in person. Whilst the informant had done prior research and grasped theories of European art the idea for the trip gave him an utmost urge to see it for himself. While viewing the artworks overwhelmed him, it gave Informant 2 a sense of understanding of the efforts required to produce art masterpieces, while also understanding the artists as a person upon viewing each and every detail of the work up close and personal. 


\section{B. Feel-Inspired}

Informant 22 felt that itinerary was unique in inspiring future filmmakers. He felt that the information given allowed the students to "walk" through the German film timeline. Considering that there were ample knowledge provided on German filmmakers and filmmaking, the informant was pleasantly surprised.

"I was shocked to see how some of their films were shot by only using one camera and without using any other equipments. Now I have a good reason not to complain that we don't have enough equipments to produce a good film. "

Informant 19 had a lot more enthusiasm for art and design upon her return to Malaysia, citing that she had expanded her knowledge on the subject matter during the trip to Berlin. She felt that through the different genres of art and design seen from the museums visited, it amazed her and had her inspired to work on more fascinating designs in the future. Further to this, a visit to a Games museum was commonly cited by the learners as nostalgic as well as inspiring, considering that it was unique, gave a feeling of dejavu thus inspiring new designs for the future.

"The Computer Games Museum was more than what I was expected. It turned out to be an arcade where you can actually play and interact with the consoles. It was definitely not a common museum. It was nice to see and learn the differences of style in the games. I'm a huge fan of computer games, looking at the old and classic games brought back the memories and nostalgia. It made me teared up a little bit and kept me inspired." - Informant 18

\section{Feel-Inspired}

Another factor that kept the learners engaged during the excursion is the sense of camaraderie and shared interests among participants of the trip. Having room to discuss and share their new knowledge with one another helped increase the likelihood of absorbing and sharing ideas to keep the momentum of experiential learning intact. Making new friends in Germany also created a sense of belonging and inclusion during the learning experience as cited by Informant 17.

"I had expected the Germans to be such welcoming people and this preconception was most positively lived up too. Not to forget, my other course mates were much more informal than I had actually imagined. We all became friends quite fast and thus we had a really great time there. Their decent manner towards the entire trip enabled us to have a gleaming time during our trip".

Similarly, Informant 2 felt that having friends close was important considering that it was his first trip away from family members and the first time experiencing the classroom overseas. While he got to experience what it's like to travel with friends, he admitted that he had a really great and memorable time in Berlin with them. Another informant shared the same sentiments with Informant 2.
"I have learned so much from this trip, not only from the places that we visited but also from the culture and the people there as well. It really widens my eyes and made me look at things differently. It was such a good experience and exposure. I'm so glad that I went to this trip, I hope that I could visit Berlin once again, with the same people if possible. "- Informant 1

\section{Reflective Observation}

Among the consistent behaviours among the learners were their reflective observation attitudes towards what they had experienced during the excursion to Berlin. While their emotions are influential towards perceptions of the excursion, they freely compare the differences of design and local culture based on their previous knowledge of other cultures. In using those elements, they watch and learn to form new knowledge during this experiential learning.

A. Watch-Reflective

Informant 8 , found that Berliners have a more fastpaced lifestyle and in her learning of the locals, health was considered a priority where the architecture provided more reasons for Berliners to commute on foot and appreciate the creative city designs.

“ Most people in Berlin take public transport. Unlike Singapore, these public transportation are scattered, making people walk from one place to another. It keeps the Germans exercising while going to work."

Informant 1 had compared her previous experience visiting foreign countries in order to feel appreciative of the city design and architecture.

"Berlin is very different from the previous destinations Beijing and Tokyo - in all senses: culture, people and art. The city wonderfully combines history and modern styles in its architecture, creating an exceptional atmosphere. “

Meanwhile, Informant 4 was very specific in her learning experience, citing that museums was a great place to attempt experiential learning where they should be immersed with the local culture and lifestyle of German people themselves.

"For me, I took away more from the cultures than what the museums can showcase. It is indeed interesting looking at Germany's past in the DDR museum to how Germans after WW2 look towards their future at the Berlinsche Galerie. The artworks at multiple museums showed that art can be appreciated by all. The view was refreshing. Everything I mentioned was amazing but none intrigued me as how Germans live their life. It was a great experience to have observed people on the side line as a tourists; but to learn their way of life, one must live among them".

\section{B. Watch-Facilitator}

An important part to note in the process of a majority of Divergers is that the group of learners in this study are heavily reliant on the impact of facilitators, educators and guidance upon completing certain tasks. The excursion to Berlin introduced many new elements of art and design 
to the participants; and are at some points a literally foreign subject to handle and deal with. Fortunately, the presence of facilitators that included the accompanying lecturers and workshop instructors helped the students in appreciating vintage and alternative forms of art.

"On the first day of the workshop, I was assigned in the team in draw and form shapes that I collected in the museum. It was fun and fascinating that we can create in $2 D$ and $3 D$ forms. On the second day, my team is given the other 2 tasks, which is recording sounds from the surroundings and make our photograms with the shapes that we cut and form. It was impressive on how the photograms was formed." - Informant 18

Further indicated by Informant 16, the participants learnt to assemble moving artwork with different colourful lights to create unique patterns on walls of the studio in which she was very focused and determined to complete.

" Along with soft music it gives you almost a magical sensation. Perhaps, our masterclass was based on the influence from this sculpture and we created monochrome pictures where shapes played the most important part. Learning how to work with basic shapes and achieving unique results can help with my future projects."

As the participants were mostly thrown outside of their comfort zones as they are involved in a programme of a foreign country, Informant 17 found that the workshop instructors played a big part in their comprehension of new technologies in design.

"Talk about the Germans there, they have been exceptionally friendly throughout the entire trip especially during workshops and have made a massive effort to overcome the language difficulty. They seem to be extremely focused, both inside and out of work. Thus, they have

entirely fulfilled my expectations in that respect and value."

\section{Watch - First Timers}

Most of the students in the excursion have never experienced learning in the form of a school trip. Informant 3, felt that as a person with very little knowledge regarding foreign countries was one of the reasons he had chosen to join the excursion to Berlin. He further mentioned that the trip was to widen his horizons by observing other cultures. Additionally, several participants felt that observing the design aesthetics of the city they are stepping in for the first time would improve their learning immensely.

"This trip was most enriching for me, allowing me to take a step back to evaluate my own strengths and weaknesses. Stepping into a new environment, changing my daily routines and exposing myself to new experiences in Germany revealed much about myself of which I was not aware before." - Informant 10
Informant 4 found that the choice of Berlin to have experiential learning through the excursion is in fact exceptional and definitely would not be achievable in Malaysia nor in the classroom walls.

"It was unique and it feels like you're in Ikea. I honestly didn't know what we had to do for the work and I was just following the flow. We had fun capturing sound effects from our environment and some of them were really funny. The highlight of the Bauhaus workshop is the photograms. It was rather interesting as I have never experienced what we did there."

It is apparent the learners involved in this excursion are independently learning based on their observations that are clearly reflected in their processing of new knowledge, particularly on the local culture that inspired the art and design environment in Berlin. It also noted that what was shared throughout the journey by watching and learning have significantly influenced the learners' emotions and attitudes towards the tasks and have encouraged them to attempt them.

\section{DISCUSSION}

As explained by Kolb [3], the learning style index consist of four principal stages of process - concrete experiences (CE), reflective observation (RO), abstract conceptualization $(A C)$, and active experimentation (AE) which are progressively connected. Each processes signifies unique cognitive characteristics through reflective practices of feeling, watching, thinking and doing. These practices then further establishes the four quadrants of learning behaviors of Diverger, Assimilator, Accommodator and Converger which are then used to measure twinned characteristics to denote the effectiveness of experiential learning which were observed significant amongst the creative design students during their visit in Berlin through their written reports.

Table 1. Learning Styles And Behavior Matrix [3]

\begin{tabular}{|l|l|l|}
\hline & $\begin{array}{l}\text { Doing (Active } \\
\text { Experimentation - AE) }\end{array}$ & $\begin{array}{l}\text { Watching (Reflective } \\
\text { Observation - RO) }\end{array}$ \\
\hline $\begin{array}{l}\text { Feeling (Concrete Experience } \\
\text { - CE) }\end{array}$ & Accommodating (CE/AE) & Diverging (CE/RO) \\
\hline $\begin{array}{l}\text { Thinking (Abstract } \\
\text { Conceptualization - AC) }\end{array}$ & Converging (AC/AE) & Assimilating (AC/RO) \\
\hline
\end{tabular}

Although the data collected showed an apparent balance across the four learning styles, the findings still indicate that majority of the students preferred to apply the reflective process of feeling (28\%) and watching (27\%) when capturing their experience throughout the learning excursion in Berlin compared to the remaining $23 \%$ of students who preferred the thinking reflective process and $22 \%$ of doing. From this data, it is found that the students are a majority of Diverger (CE/RO) followed by Converger learners (AC/AE). Diverger learners are the deep thinkers with strong imagination and emotional flow. Their learning process rely heavily on the way they feel about the experiences and how it affect their emotional being. These learners will often view their experiences from different perspectives and will most 
likely to generate a lot of creative ideas. Converger learners on the other hands are the practical individuals where they rely on the learning process of thinking and doing. Their preferences to technical outputs mean that they prefer doable practices of theories and ideas rather than Divergers' wide imaginative scope. Emotions are clearly are influential towards perceptions of the excursion where informants watch and learn to form new knowledge. Chapman et al. [24] listed one of the characteristics that should be present in an activity for it to be defined as experiential is creating emotional investment; where one needs to be immersed in the experience beyond doing what they feel is required for them. This can be seen with Informant 4 that cited museums as a great place to attempt experiential learning where they should be immersed with the local culture and lifestyle of German people themselves. Also the relationship that exists within the activities is defined as experiential. During this excursion, the presence of facilitators in the form of accompanying lecturers and workshop instructors, together with their peers helped the students handle the subject that are foreign to them. Informant 1 and 2 felt that having peers together during the trip enables them to widen their perspective and made them look at things differently. Thus, it can be said that the practice of experiential learning is applicable for creative design learners due to the significant relationships built through their emotions and observations of their environment, peers and facilitators. This further determines the importance and relevance of traditional teaching pedagogies to creative design learners despite the prevalence of teaching technologies and virtual learning. The human aspect is still central and instrumental in shaping the attitudes and behaviours of learners that inspire and motivate them to improve themselves and produce learning outputs that achieve the module learning outcomes.

\section{CONCLUSION}

In order to transition into the workforce, one of the necessary skills requires to help university stays relevant to the students is through experiential learning [25]. This paper had demonstrated that experiential learning is relevant and can be useful in future academic endeavours especially in the design field. The identification of Diverger and Converger learners from this research reaffirms the importance of conceptual and technical aspect of creative idea generation in design studies. Even so, further studies are recommended to strengthen experiential learning theories as this research only concentrated on one type of design learning activity.

\section{REFERENCES}

[1] L. Cameron, "How learning designs, teaching methods and activities differ by discipline in Australian universities.," $J$. Learn. Des., vol. 10, no. 2, pp. 69-84, 2017.

[2] S. Grapragasem, A. Krishnan, and A. N. Mansor, "Current trends in Malaysian higher education and the effect on education policy and practice: An overview," Int. J. High. Educ., vol. 3, no. 1, p. 85, 2014.

[3] D. A. Kolb, Experiential learning: Experience as the source of learning and development. FT press, 2014.

[4] M. Chavan, "Higher education students' attitudes towards experiential learning in international business," J. Teach. Int. Bus., vol. 22, no. 2, pp. 126-143, 2011.
[5] M. Schwartz, "Best practices in experiential learning," Learn. Teach. Off., 2012.

[6] L. H. Lewis and C. J. Williams, "Experiential learning: Past and present," New Dir. adult Contin. Educ., vol. 1994, no. 62, pp. 516, 1994.

[7] Taylor's University, “TAYLOR'S GRADUATE CAPABILITIES | Taylor's University." [Online]. Available: https://university.taylors.edu.my/about-taylors/future-

prooflearning/taylors-graduate-capabilities. [Accessed: 30-May2017]. [8] A. Y. Kolb and D. a Kolb, "The Kolb Learning Style Inventory - Version 3. 12005 Technical Specifi cations," LSI Tech. Man., pp. 1-72, 2005.

[9] J. Dewey, Experience and education. Simon and Schuster, 2007.

[10] L. S. Daloz, Effective teaching and mentoring, no. 374.973 D144e. California, US: Bass Publishers, 1986, 1986.

[11] F. J. Fernández-Cruz and M. J. Fernández-Díaz, "Generation Z's Teachers and their Digital Skills $=$ Los docentes de la Generación Z y sus competencias digitales," Comunicar, vol. 24, no. 46, pp. 97-105, 2016.

[12] M. Ranai, "2018 MANDATE: Embracing Industry 4.0," Ministry of Higher Education, 2018. [Online]. Available: http://news.moe.gov.my/2018/01/27/2018-mandateembracingindustry-4-0/. [Accessed: 01-Jul-2018].

[13] J. C. Richardson, A. A. Koehler, E. D. Besser, S. Caskurlu, J. Lim, and C. . Mueller, "Conceptualising and investigating instructor presence in online learning environments," Int. Rev. Res. Open Distrib. Learn., vol. 16, no. 3, pp. 256-297, 2015.

[14] X. Zhang, S. Jiang, P. Ordóñez de Pablos, M. D. Lytras, and Y. Sun, "How virtual reality affects perceived learning effectiveness: a task-technology fit perspective," Behav. Inf. Technol., vol. 36, no. 5, pp. 548-556, 2017.

[15] B. Akkoyunlu and M. Yilmaz-Soylu, "A study of student's perceptions in a blended learning environment based on different learning styles.," Educ. Technol. Soc., vol. 11, no. 1, pp. 183-193, 2008.

[16] P. Alves, L. Miranda, and C. Morais, "Learning Styles and Access to Virtual Learning Environments in the Academic Performance," in European Conference on e-Learning, 2014, pp. 25-33.

[17] P. Honey and A. Mumford, Learning styles questionnaire Organization Design and Development, Incorporated, 1989.

[18] I. B. Myers, M. H. McCaulley, N. L. Quenk, and A. L. Hammer, MBTI manual: A guide to the development and use of the MyersBriggs Type Indicator, vol. 3. Consulting Psychologists Press Palo Alto, CA, 1998.

[19] G. Pask and B. C. E. Scott, "Learning strategies and individual competence," Int. J. Man. Mach. Stud., vol. 4, no. 3, pp. 217253, 1972.

[20] N. Manochehr, "The influence of Learning Styles on Learners in E-Learning Environments: An Empirical Study," Comput. High. Educ. Econ. Rev., vol. 18, pp. 10-14, 2006.

[21] A. Y. Kolb and D. A. Kolb, "Learning styles and learning spaces: Enhancing experiential learning in higher education," Acad. Manag. Learn. Educ., vol. 4, no. 2, pp. 193-212, 2005.

[22] M. Schreier, Qualitative content analysis in practice. Sage Publications, 2012.

[23] R. Racelis, M. Iii, R. R. Maaliw III, R. Racelis, and M. Iii, "Classification of Learning Styles in Virtual Learning Environment using Data Mining: A Basis for Adaptive Course Design," pp. 56-61, 2016.

[24] S. Chapman, P. McPhee, and B. Proudman, "What is experiential education?," J. Exp. Educ., vol. 15, no. 2, pp. 1623, 1992.

[25] J. A. Cantor, "Co-operative education and experiential learning," Wall\&Emerson, Inc. Toronto, 1995. 